\title{
The evaluation of cost-of-illness due to use of cost- of-illness-based chemicals
}

\author{
Jiyeon Hong ${ }^{1,2}$, Yongjin Lee ${ }^{3}$, Geonwoo Lee ${ }^{3}$, Hanseul Lee ${ }^{3}$, Jiyeon Yang ${ }^{3}$ \\ ${ }^{1}$ Enterprise Risk Service Deloitte Anjin LLC, Seoul; ${ }^{2}$ Department of Environmental Engineering, Yonsei University, Wonju; \\ ${ }^{3}$ Institute for Environmental Research, Yonsei University Health System, Seoul, Korea
}

\begin{abstract}
Objectives This study is conducted to estimate the cost paid by the public suffering from disease possibly caused by chemical and to examine the effect on public health.

Methods Cost-benefit analysis is an important factor in analysis and decision-making and is an important policy decision tool in many countries. Cost-of-illness (COI), a kind of scale-based analysis method, estimates the potential value lost as a result of illness as a monetary unit and calculates the cost in terms of direct, indirect and psychological costs. This study estimates direct medical costs, transportation fees for hospitalization and outpatient treatment, and nursing fees through a number of patients suffering from disease caused by chemicals in order to analyze COI, taking into account the cost of productivity loss as an indirect cost.

Results The total yearly cost of the diseases studied in 2012 is calculated as 77 million Korean won (KRW) per person. The direct and indirect costs being 52 million KRW and 23 million KRW, respectively. Within the total cost of illness, mental and behavioral disability costs amounted to 16 million KRW, relevant blood immunological parameters costs were 7.4 million KRW, and disease of the nervous system costs were 6.7 million KRW.

Conclusions This study reports on a survey conducted by experts regarding diseases possibly caused by chemicals and estimates the cost for the general public. The results can be used to formulate a basic report for a social-economic evaluation of the permitted use of chemicals and limits of usage.
\end{abstract}

Keywords Cost-benefit analysis, Cost-of-illness, Diseases caused by chemicals

\author{
Correspondence: Jiyeon Yang \\ 50-1 Yonsei-ro, Seodaemun-gu, \\ Seoul 120-752, Korea \\ Tel: $+82-2-2228-1896$ \\ Fax: +82-2-392-0239 \\ E-mail: jyyang67@yuhs.ac
}

Received: January 8, 2015

Accepted: March 3, 2015.

Published online: June 12, 2015

This article is available from: http://e-eht.org/

\section{Introduction}

Accidents and disease have increased at a constant and steady rate alongside the growth of industrial development and the use of chemicals. Due to this, a policy to limit the use of chemicals is being implemented throughout the world.

Following this trend, South Korea (hearafter Korea) is planning to pass the Korean Registration Evaluation Authorization and Restriction of Chemicals (REACH), which is based on risk assessment that not only looks at the hazards of chemicals but also the risk of exposure, and this is planned to be implemented from 2015.

It follows that there should be proper support provided in order to regulate chemical use through policing the usage and limitation of chemicals.

Cost-benefit analysis is an important factor in analysis and decision-making and is an important policy decision tool in many countries. The cost element comprises a variety of costs and can be divided into direct and indirect costs. Direct costs are made up of compliance costs, government regulation costs, social welfare costs, and relocation costs. The benefit element refers to the positive effect towards improving social members' welfare and 
is regulated and reformed by policy.

According to the introduction of REACH by the European Union (EU), the estimation of benefits related to health is studied in two parts. One part is the effect of health improvement on workers in the workplace and the other part is the effect of health improvement on the public

The effect of health improvement for workers in the workplace, Risk and Policy Analysts Ltd., is estimated to incur a cost of 176 to 544 hundred million euros, which will cover five diseases, including occupational cancer [2]. The effect of the health improvement of the public is estimated to incur a cost of about a 224 to 513 hundred million euros. According to Pearce and Koundouri [1], when considering the reduction in medical costs the estimated figure was 48 to 201 hundred million euros and, furthermore [3], the European Commission estimates that the benefit from REACH will amount to the value of about 500 hundred million euros within 30 years.

There is a domestic study by Bae [4] that states that the estimated benefit from the Korea REACH act, based on the cost of work related diseases and preventable occupational disease calculates a medical cost of 15.35 million Korean won (KRW) per 1 unit of disability-adjusted life year in the national healthcare expenditure reduction.

With regards to the effects of chemicals on the body, the benefit analysis divides the benefits into cancer death benefit and the burden of disease benefit.

When we estimate the benefit through analysis of disease there is a premise that the disease will not necessarily lead to death. The benefit also estimates how much the environment policy can influence disease remission and its economic worth.

This study is specifically conducted to estimate the cost paid by the public suffering from diseases possibly caused by chemicals, and to check the effect on public health.

\section{Materials and Methods}

Cost-of-illness (COI), which is one of the effective benefit estimation methods for disease, is widely used in health and medical

Table 1. List of cost items

\begin{tabular}{lllc}
\hline Item & Details & Reference \\
\hline Medical cost & $\begin{array}{c}\text { Direct medical } \\
\text { cost }\end{array}$ & $\begin{array}{l}\text { Cost-sharing } \\
\text { Medical insurance expenses } \\
\text { per one person/case }\end{array}$ & 7 \\
$\begin{array}{c}\text { Indirect medical } \\
\text { cost }\end{array}$ & $\begin{array}{l}\text { Transportation fees } \\
\text { Nursing fees }\end{array}$ & 8,10 \\
$\begin{array}{c}\text { Cost of productivity loss } \\
\text { (classification of outpatient and } \\
\text { inpatient) }\end{array}$ & $\begin{array}{l}\text { Daily labor costs } \\
\text { Average days to medical } \\
\text { treatment }\end{array}$ & 9 \\
\hline
\end{tabular}

areas as a methodology for measuring the socioeconomic COI.

COI, which can be said to be a kind of scale-based analysis method, estimates the potential value lost through illness as a monetary unit and calculates the cost in terms of direct, indirect and psychological costs.

The key advantage of COI is that it is easily available, uses reliable materials, and provides an exact sensitivity analysis to measure a material's change in order to calculate social costs.

In the cost of disease, direct costs such as direct medical cost refer to real treatment costs, such as treatment, cure, and longterm treatment and indirect medical costs refer to elements in recovery, such as subsidiary nursing fees for treatment and transportation fees paid by patients visiting healthcare centers.

Indirect costs are the productivity loss occurring as a result of death or disease. Psychological costs are related to the pain or low quality of life suffered by the patients, family, or friends. However, this is excluded in the disease cost estimation because the cost is difficult to quantify $[5,6]$.

This study estimates direct medical costs, transportation fees for hospitalization and outpatient treatment, and nursing fees through those patients suffering from diseases caused by chemical in order to analyze the COI, taking into account the cost of productivity loss as an indirect cost. The list of cost items are shown in Table 1.

\section{Results}

To calculate the medical expenses of diseases possibly related to certain chemicals, international organizations, non-Korean environment analysis for disease, as well as domestic environmental disease health experts and relevant stakeholders selected some diseases through the Delphi survey. Some 298 diseases, divided into the 21 areas, are classified by the National Health Insurance Service of Korea [7].

Seventeen hundred experts connected with contaminant management technology, risk management and toxicity evaluation conducted a survey by e-mail. A total of 71 people responded to the survey (response rate $4.2 \%$ ), and the result of the survey was medically reviewed by doctors of family medicine.

The diseases possibly caused by chemicals were divided into 16 categories except for neoplasm diseases, infectious diseases, external cause diseases, below $10 \%$ of expert's response rate, and disease not connected with chemicals.

Of the 298 diseases, the Korean Standard Classification of Diseases excluded those not related to chemicals. The Delphi survey, about environmental disease caused by chemicals, was conducted by environmental and health experts.

None of the diseases received any response. There were plenty 
Table 2. Cost-of-illness estimation

\begin{tabular}{|c|c|}
\hline Item & Details \\
\hline Direct medical cost & $\Sigma$ (treatment amount×patients) \\
\hline Indirect medical cost & $\begin{array}{l}\text { Transportation costs=(average visit days } \times \text { average one-way transportation costs)+(average number of hospitalization } \\
\times \text { average one-way transportation costs) } \\
\text { Nursing costs=hospitalization days per patients } \times 1 \text { day average wage }\end{array}$ \\
\hline $\begin{array}{l}\text { Cost of productivity loss } \\
\text { (classification of outpatient and inpatient) }\end{array}$ & 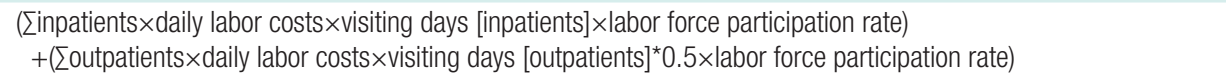 \\
\hline
\end{tabular}

of answers regarding respiratory organs (about 96\%) and integumentary systems, but there was a low response rate regarding diseases connected to the ear and tuberculosis.

An analysis conducted by experts excluded diseases, including vitamin A deficiency, varicose veins, paralytic ileus and intestinal obstruction without hernia, diverticulosis, redundant prepuce, phimosis and paraphimosis, dystocia, congenital infection and parasitic diseases, malnutrition, other hernia, female genital prolapse, postpartum bleeding, other tuberculosis, inguinal hernia, other dorsopathies, single spontaneous delivery, birth trauma, acquired deformities of limb, other articular disorders, and lumbar and other Intervertebral disc disorder.

Also any disease caused by neoplasm leading to death is not considered as an environmental disease caused by chemicals.

Annual medical expenses for one person are calculated with patients and insurance corporations sharing the costs, which are based on treatment costs for illnesses possible caused by chemicals.

Medical costs were calculated separately for inpatients and outpatients and comprised the cost of treating a patient and the price of drugs.

In the case of nursing fees included in indirect medical costs for inpatients, the patients suffer a loss of earnings because someone, such as an immediate family member or relative, has to care for inpatients if they don't hire a caregiver. Nursing fees can be estimated on an average daily cost of $33500 \mathrm{KRW}$, based on the Ministry of Health and Welfare's announcement in 2010 [8].

Spending on the average round-trip transportation fare for healthcare center visits is based on the health panel survey material of 2010. Inpatients average a transportation fare of 7597 KRW (including guardian transportation fare), which is multiplied with number of round-trips. In the case of outpatients, their one-off transportation fare, $777 \mathrm{KRW}$, is also multiplied in the case of a number of round-trips [10].

There is not enough statistical material regarding the number of hospitalizations, so when calculating the transportation fee, the average number of hospitalizations by age in the Korean Health Panel survey of Korea Institute for Health and Social Affairs of 2011 is used. In the case of hospitalization, the transportation fee is multiplied by 2 (patient and protector).

In the case of transportation fees and nursing fees, there is no statistical material for disease available from the National Health Insurance Service of Korea for the baseline year 2012. Therefore the fees for transportation and nursing were corrected according to the price equivalent index of 2010. The cost of productivity loss as an indirect cost estimates economical productive capacity loss. Generally, the estimation measures productivity loss when a worker with a disease can't work or it affects their workplace. When the work is temporarily stopped, the cost is calculated by multiplying lost time by the daily wage. Productivity loss also contains not only lost time through nursing but also lost work in the workplace. Productivity loss costs estimate annual productivity loss, cost of a lost work period through disease, taking into account the economically active population survey materials, such as work days, working hours, the monthly salary and the average income in the yearbook of employment and labor statistics of the Ministry of Employment and Labor [9].

The legal working age in Korea is 15 years old. The cost of productivity loss is estimated based on an economically active population related to age and the number of patients related to age (over 15 years old). The COI estimation is shown in Table 2.

As a result, the calculated cost of all of the diseases selected in 2012 is 77 million KRW per person. The direct and indirect costs being 52 million KRW and 23 million KRW, respectively.

In the total disease cost, mental and behavioral disability costs amount to 16 million KRW, relevant blood immunological parameters costs are 7.4 million KRW, and diseases of the nervous system costs are 6.7 million KRW.

Direct costs were calculated for mental and behavioral disability (9.6 million KRW), relevant blood immunological parameters (6.4 million KRW), and the circulatory system (4.8 million KRW). Indirect costs were mental and behavioral disability (6.9 million KRW), diseases of the nervous system (2.1 million KRW) and tuberculosis (1.8 million KRW).

In conclusion, this study estimates the costs of diseases contracted from harmful chemicals by applying COI.

One social benefit of the support regulation policy is the calculation of every single person's satisfaction and welfare in terms of monetary value. However, it is too difficult to calculate the benefit of environmental policy by comparison with the general economic policy. 
Therefore, in order to establish a level of usage and restriction of chemicals, there should be a cost-benefit analysis and the results of this analysis are needed to be supported with examples.

This study conducted a survey conducted by experts regarding diseases possibly caused by chemicals and estimates the disease cost for the general public. The results of this study can be used to formulate a basic report for a socioeconomic evaluation on the permitted use of chemicals and limits of usage.

In the future, we plan to undergo a peer review but a study of illness due to chemicals derived through a causal relationship study of the chemical and diseases is needed.

\section{Acknowledgements}

This study was supported by the Korea Ministry of Environment (MOE) as "MOE's R\&D Program on environmental technology development” (no. 412-111-005).

\section{Conflict of Interest}

The authors have no conflicts of interest with material presented in this paper.

\section{References}

1. Pearce D, Koundouri P. The social costs of chemicals: the cost and benegits of future chemicals policy in the European Union. Godalming: World Wildlife Fund; 2003, p. 28-40.

2. Risk and Policy Analysts Ltd. Assessment of the impact of the new chemicals policy on occupational health: final report; 2003 [cited 2015 Apr 2]. Available from: http://ec.europa.eu/environment/ chemicals/reach/pdf/background/finrep_occ_health.pdf.

3. Commission of the European Communities. Extended impact assessment; 2003 [cited 2015 Apr 3]. Available from: http:/ /ec.europa. eu/enterprise/sectors/chemicals/files/reach/eia-sec-2003_1171_ en.pdf.

4. Lee JB. Cost-benefit analysis in accordance with pre-legislation 'registration and evaluation of chemicals'(focused on direct costs) [dissertation]. Seoul: Korea University; 2012, p. 30 (Korean).

5. Tarricone R. Cost-of-illness analysis. What room in health economics? Health Policy 2006;77(1):51-63.

6. Rice DP. Estimating the cost of illness. Am J Public Health Nations Health 1967;57(3):424-440.

7. Kim JD, Kang YK. National health insurance statistical yearbook. Seoul: Health Insurance Review and Assessment Service; 2012, p. 376-555 (Korean).

8. Shin YS, Hwang DK, Namgung EH, Min IS, Yoon SJ, Jung HS. A study on institutionalization of hospital caregiver service. SeoulMinistry of Health and Welfare; 2010, p. 64 (Korean).

9. Ministry of Employment and Labor. Yearbook of employment and labor statistics 2013. Seoul: Ministry of Employment and Labor; 2013, p. 272 (Korean).

10. Korea Institute for Health and Social Affairs. The basic analysis report of Korean health panel survey. Seoul: National Health Insurance Service; 2011, p. 89-90 (Korean). 